\title{
SOEP
}

SOEPpapers

on Multidisciplinary Panel Data Research

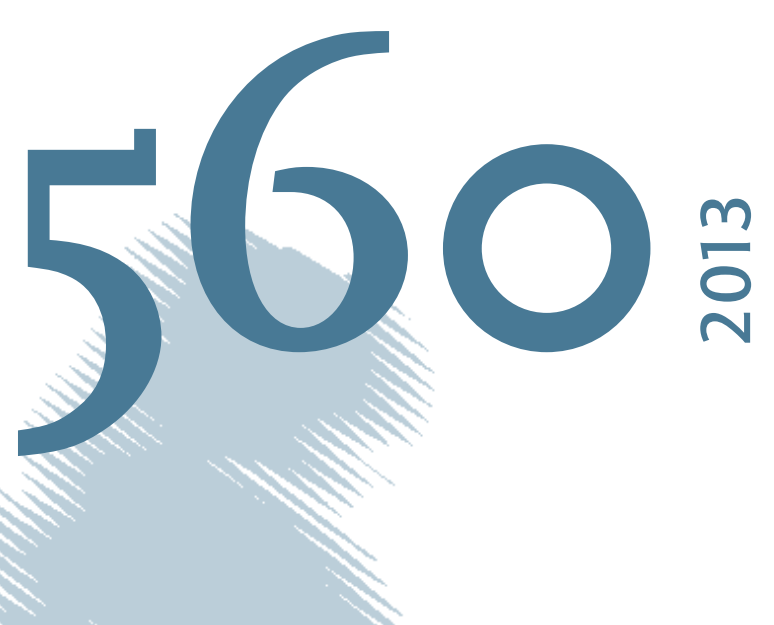

\section{Nominal or Real? The Impact of Regional Price Levels on Satisfaction with Life}

Thomas Deckers, Armin Falk, Hannah Schildberg-Hörisch 


\section{SOEPpapers on Multidisciplinary Panel Data Research}

at DIW Berlin

This series presents research findings based either directly on data from the German SocioEconomic Panel Study (SOEP) or using SOEP data as part of an internationally comparable data set (e.g. CNEF, ECHP, LIS, LWS, CHER/PACO). SOEP is a truly multidisciplinary household panel study covering a wide range of social and behavioral sciences: economics, sociology, psychology, survey methodology, econometrics and applied statistics, educational science, political science, public health, behavioral genetics, demography, geography, and sport science.

The decision to publish a submission in SOEPpapers is made by a board of editors chosen by the DIW Berlin to represent the wide range of disciplines covered by SOEP. There is no external referee process and papers are either accepted or rejected without revision. Papers appear in this series as works in progress and may also appear elsewhere. They often represent preliminary studies and are circulated to encourage discussion. Citation of such a paper should account for its provisional character. A revised version may be requested from the author directly.

Any opinions expressed in this series are those of the author(s) and not those of DIW Berlin. Research disseminated by DIW Berlin may include views on public policy issues, but the institute itself takes no institutional policy positions.

The SOEPpapers are available at

http://www.diw.de/soeppapers

\section{Editors:}

Jürgen Schupp (Sociology, Vice Dean DIW Graduate Center)

Gert G. Wagner (Social Sciences)

Conchita D'Ambrosio (Public Economics)

Denis Gerstorf (Psychology, DIW Research Director)

Elke Holst (Gender Studies, DIW Research Director)

Frauke Kreuter (Survey Methodology, DIW Research Professor)

Martin Kroh (Political Science and Survey Methodology)

Frieder R. Lang (Psychology, DIW Research Professor)

Henning Lohmann (Sociology, DIW Research Professor)

Jörg-Peter Schräpler (Survey Methodology, DIW Research Professor)

Thomas Siedler (Empirical Economics)

C. Katharina Spieß (Empirical Economics and Educational Science)

ISSN: 1864-6689 (online)

German Socio-Economic Panel Study (SOEP)

DIW Berlin

Mohrenstrasse 58

10117 Berlin, Germany

Contact: Uta Rahmann | soeppapers@diw.de 


\title{
Nominal or Real? The Impact of Regional Price Levels on Satisfaction with Life*
}

\author{
Thomas Deckers \\ University of Bonn \\ and IZA
}

\author{
Armin Falk \\ University of Bonn \\ and IZA
}

\author{
Hannah Schildberg-Hörisch \\ University of Bonn
}

\begin{abstract}
We study the effect of real versus nominal income on life satisfaction. According to economic theory real income, i.e., nominal income adjusted for purchasing power, should be the relevant source of life satisfaction. Previous work, however, has only studied the impact of nominal income. We use a novel data set comprising about 7 million data points that are used to construct a price level for each of the about 400 administrative districts in Germany. We estimate a fixed effects model that controls for individual and local heterogeneity other than the price level. Our results show that higher price levels significantly reduce life satisfaction for individuals in the four lowest deciles of the income distribution. Furthermore, our findings suggest that people do not perceive money as neutral: the loss in life satisfaction caused by a higher price level is much larger than the loss in life satisfaction induced by a corresponding decrease in nominal income. Our results provide an argument in favor of regional indexation of government transfer payments such as social welfare benefits.
\end{abstract}

JEL Classification: D60, C23, D31

Keywords: life satisfaction, price index, neutrality of money, redistribution

Corresponding author:

Thomas Deckers

Department of Economics

University of Bonn

Adenauerallee 24-42

53113 Bonn

Germany

E-mail: thomas.deckers@uni-bonn.de

\footnotetext{
* We thank Rupert Kawka for providing the price index data and for valuable comments while working with them and Christoph Hanck, Andrew Oswald, Alois Stutzer and Rainer Winkelmann for insightful comments.
} 


\section{Introduction}

Among the determinants of life satisfaction, income is of fundamental interest and importance to economists. Consequently, studies on the effect of income on life satisfaction are abundant. They range from cross-country studies on the relationship between gross national product and average reported life satisfaction to analyses of the effect of individual income on individual life satisfaction (for survey articles see, e.g., Oswald (1997), Frey and Stutzer (2002), Di Tella and MacCulloch (2006), Clark et al. (2008), Dolan et al. (2008), and Stutzer and Frey (2010)). ${ }^{1}$ Lacking adequate data on purchasing power, all research on individual life satisfaction conducted so far has used nominal income as explanatory variable. According to microeconomic theory, however, individuals derive satisfaction not from nominal income, but from consumption of goods that they can afford with their income. Hence, real income, i.e., nominal income adjusted for purchasing power, is the appropriate variable to measure the effect of income on life satisfaction.

This paper therefore studies whether differences in local price levels have an effect on individual satisfaction with life once we control for nominal income and local heterogeneity. ${ }^{2}$ To this end, we match two sources of data: the first is a novel and very comprehensive data set on local price levels in Germany, a price index covering each of Germany's 393 administrative districts. The price index reveals substantial price differences within Germany (up to 37\%) and is, to our knowledge, unique at such a disaggregated level. Information used to construct the price index comprises more than 7 million data points. Detailed knowledge about prices at a disaggregate level is a prerequisite for studying the effects of prices on life satisfaction. Information on prices at a more aggregate administrative level (i.e., federal states) would not be sufficient. To illustrate, note that geographically both the cheapest and the most expensive German district are located in the same federal state. We match our price index data with data from the German Socio-Economic Panel (SOEP) which includes a question on individual life satisfaction, a wide range of control variables, and district identifiers. The SOEP is a household panel survey which is representative of the German population. About 22,000 individuals in about 12,000 households are interviewed each year. To identify the effect of prices on life satisfaction, we use an individual

\footnotetext{
${ }^{1}$ Besides studying absolute income, the role of relative income (e.g., Clark and Oswald (1996), Luttmer (2005), Ferrer-i Carbonell (2005), Fliessbach et al. (2007)) and aspiration income (e.g., Stutzer (2004)) for individual life satisfaction has been explored.

${ }^{2}$ We adjust nominal income for inflation, i.e., variation of prices over time. In contrast, local price levels capture variation of prices over districts at a given point in time.
} 
fixed effects regression approach. Additionally, we include district dummies that capture district heterogeneity other than the price level.

Our first main finding is that there is a 'purchasing power effect': for a given nominal income, a higher price level reduces satisfaction with life. While the purchasing power effect is present in the population as a whole, it is statistically significant only for the $40 \%$ poorest individuals in our sample. The effect sizes are substantial. Consider an individual at the $25 \%$ income quantile with a given nominal income. Moving from a district with average German price level to a $10 \%$ more expensive district reduces life satisfaction by 0.53 points on an 11 point scale. This resembles the average effect (0.6 points) of having a full-time job instead of being unemployed.

Our second main finding is evidence for non-neutrality of money. In particular, we find that the effect of a $10 \%$ price increase exceeds the effect of a corresponding (i.e., 9.1\%) decrease in nominal income, although both result in the same real income. For example, a person at the $25 \%$ income quantile living in a district with mean price level only loses 0.06 points on the life satisfaction scale for a $9.1 \%$ decrease in nominal income - compared to a loss of 0.53 points for a corresponding increase in the price level. We also provide formal tests for neutrality of money and reject the null hypothesis of neutrality of money for the $40 \%$ poorest individuals in our sample for whom we find a significant purchasing power effect. Note that the observed non-neutrality is contrary to what one might have expected: a larger effect of a decrease in nominal income than of a corresponding price increase. A similar effect, however, is documented in Boes et al. (2007).

Our results provide new insights for the literature on individual life satisfaction and have important policy implications. Our first result that differences in the price level have a more pronounced effect on life satisfaction for poorer people adds to the well-established fact that life satisfaction is concave in nominal income. The literature on life satisfaction has repeatedly documented the existence of diminishing marginal utility of nominal income, i.e., a concave relationship of reported life satisfaction and nominal income. ${ }^{3}$ Layard et al. (2008), e.g., report that one extra pound increases life satisfaction only one tenth as much for a rich person as for a person being one tenth as rich. It therefore makes perfect sense that the effect of purchasing power on life satisfaction depends on the location in the income distribution, simply because people with low income are located at the steepest part of the life satisfaction-income relation. Hence, they are particularly sensitive to price changes.

\footnotetext{
${ }^{3}$ As Oswald (2008) points out, this claim implicitly assumes that reported life satisfaction is linear in actual life satisfaction.
} 
In terms of policy implications, our results provide an argument in favor of regional indexation of government transfer payments, in particular of those transfers that target low income groups such as unemployment and social welfare benefits. Our results also question country-wide uniform public sector or minimum wages. They show that not adjusting nationwide payments to regional price differences treats equals unequally in terms of individual life satisfaction.

Additionally, our study adds to uncovering how people perceive nominal and real quantities. From an economic policy perspective, perception of real versus nominal terms is, for example, important for determining optimal inflation rates to be targeted by central banks (Akerlof and Shiller, 2009). Economic theory usually assumes neutrality of money, i.e., that people think and act in terms of real quantities and are not guided by nominal quantities. In our case, neutrality of money implies that a price decrease should affect life satisfaction in the same way as an increase in nominal income that exactly offsets the price decrease in real income terms. In principle, deviations from neutrality of money could go in two directions. People could either overreact to changes in nominal income or to changes in prices. An overreaction to nominal quantities is usually referred to as money illusion. Fisher (1928) was the first to suggest that people may exhibit money illusion. Money illusion was basically ignored in economic research until it was again studied by Shafir et al. (1997) who report evidence in favor of money illusion using questionnaire and experimental data. ${ }^{4}$ In our context, money illusion would imply that a $10 \%$ increase in nominal income, e.g., increases life satisfaction more strongly than a corresponding (i.e., 9.1\%) price decrease.

In contrast, an overreaction to prices would imply that a decrease in prices increases life satisfaction more than a corresponding increase in disposable income. An overreaction to prices is plausible if prices are more salient than disposable nominal income. Income is usually paid monthly, often directly accrues to a bank account, and changes only infrequently. Furthermore, disposable income has many less salient components such as taxes and government transfer payments. To the contrary, prices are experienced daily, at every instance of buying. Importance of salience effects is documented in Chetty et al. (2009), Blumkin et al. (2012), and Finkelstein (2009) who provide evidence that consumers fail to sufficiently take into account less salient aspects in decision making. Chetty et al. (2009) show that consumers underreact to less salient taxes, i.e.,

\footnotetext{
${ }^{4}$ Weber et al. (2009) provide neuroeconomic evidence in favor of money illusion using functional magnetic resonance imaging. Using a laboratory experiment, Fehr and Tyran (2001) show that even a small extent of money illusion at the individual level may be sufficient to result in a large aggregate bias after a negative nominal shock.
} 
taxes that are not included in price tags. ${ }^{5}$ In a lab experiment, Blumkin et al. (2012) find similar evidence. They show that less salient taxes distort the labor-leisure allocation. Finkelstein (2009) shows that drivers are less aware of tolls that are paid electronically and, as a consequence, driving is less elastic with respect to tolls that are paid electronically instead of manually.

In contrast to most of the literature, our results on neutrality of money are based on yearly income data, i.e., large stakes for an individual. We find evidence that life satisfaction of people with a lower nominal income tends to react much stronger to changes in the price level than to corresponding changes in (possibly less salient) nominal disposable income. The only other study on subjective well-being (concerning satisfaction with income) and price levels we are aware of is Boes et al. (2007). They focus on whether people exhibit money illusion and do not investigate the impact of real as opposed to nominal income on life satisfaction. Using SOEP data, they study the effect of price levels on income satisfaction and use much more aggregate data on price levels, i.e., price levels for 13 out of the 16 German federal states. Boes et al. (2007) do not find evidence for money illusion, but a (statistically insignificant) overreaction to prices, a result that points into the same direction as our second main finding on non-neutrality of money. Senik (2004) analyzes whether reference group income influences life satisfaction due to social comparisons or by providing information used to form expectations about one's own future income. She constructs 'real' income measures by using information on regional poverty lines of 38 Russian regions that are provided by the Russian longitudinal monitoring survey (RLMS) data set. Compared to our data, regional prices refer to much larger geographical units and are only available for comestible goods that account for about $9 \%$ of components of the price index we use.

The remainder of the paper is organized as follows: section 2 describes both sources of data, section 3 explains our empirical strategy, and section 4 presents our results and several robustness checks. We discuss implications of our results and conclude in section 5 .

\section{Data}

We use information on price levels of all 393 German districts ('Kreise') to obtain a precise measure of individual real income. The districts constitute administrative units comprising one or more cities and their surroundings. The districts are the smallest division of Germany for which

\footnotetext{
${ }^{5}$ In Germany, the convention is to post all prices including taxes. Thus, in our data prices are a very transparent expression of real quantities.
} 
it is feasible to collect detailed price data, because in smaller units some of the products contained in the price index will not be available. The data on prices at district level have been collected by the German Administrative Office for Architecture and Comprehensive Regional Planning. Kawka et al. (2009) describe the data set, its collection and descriptive results on price levels in great detail.

The price index is constructed based on the basket of commodities used by the German Federal Statistical Office to calculate the German inflation rate. Table 1 lists the most important classes of goods that this basket of commodities contains. In terms of classes of goods, the price index covers $73.2 \%$ of this basket. In particular, more than 7 million data points on prices of 205 commodities have been collected at the district level. Prices range from obvious candidates such as rental rates, electricity prices, or car prices to such detailed ones as dentist fees, prices for cinema tickets, costs for foreign language lessons, or entry fees for outdoor swimming pools. We are not aware of any other data source from any other country that provides such a comprehensive price index for a similarly detailed geographical resolution.

With these data, a price index is constructed that provides an overall price level for each district. When constructing a price index, a weight needs to be attached to each individual commodity measuring its share of the whole basket of commodities. The price index is defined using the weights that are used by the German Federal Statistical Office to construct the inflation rate. These weights are inferred from a household survey with 53,000 households. These households are asked about their income and consumption habits. With these weights, the price index is constructed as an arithmetic mean. The weighting is the same for each individual and each district, i.e., it does not adjust for different consumption habits of rich and poor people, men and women, families and singles, young and old people or, more generally, for different individual or regional preferences for consumption. Such an approach certainly introduces some measurement error. Due to feasibility, it is, however, the standard approach in economics concerning price indices and also inflation rates. A clear advantage of this approach is that it allows for a direct comparison of different regional price levels and for a straightforward interpretation of the price index: intuitively, we can ask what 'an average individual traveling through Germany' would need to pay for a given consumption bundle in each district.

Since collecting such comprehensive data cannot be managed in a single year, the data were gathered in the years 2004 to 2009, with most of the data, roughly $85 \%$, being collected from 2006 to 2008. The data are used to build a single time-invariant price level for each district. The 
Table 1: Main components of the basket of commodities

\begin{tabular}{lc}
\hline \hline Commodity group & \%o of whole basket \\
\hline Rent for dwellings (including rental value for owner-occupied dwelling) & 203.30 \\
Comestible goods & 89.99 \\
Goods and services for privately used vehicles & 75.57 \\
Electricity, gas, and other fuels & 59.82 \\
Clothing & 39.42 \\
Purchase of vehicles & 37.50 \\
Water supply and other dwelling related services & 33.04 \\
Food services & 32.12 \\
Leisure and cultural services & 28.99 \\
Telecommunication & 27.12 \\
Furniture, interior equipment, carpeting, and other floor coverings & 26.50 \\
Insurance services & 24.88 \\
Tobacco products & 22.43 \\
Personal hygiene & 21.54 \\
Leisure products, garden products, pets & 21.53 \\
Audiovisual, photographic, and information-processing devices and related equipment & 19.01 \\
\hline \hline
\end{tabular}

Reproduced from the German Federal Statistical Office (2005) (see http://www.destatis.de/jetspeed/portal/ cms/Sites/destatis/Internet/DE/Content/Statistiken/Preise/Verbraucherpreise/WarenkorbWaegungsschema /Waegungsschema,property=file.pdf). Displayed commodity groups account for about $750 \%$ of the whole basket of commodities.

procedure implicitly assumes that the relative price level of each district remains constant over the period of study. This assumption is quite realistic. For example, the correlation coefficient of rental prices at the district level in 2004 and 2008 is 0.989 . With a share of about $20 \%$, rents are by far the most important single component of the price index.

The price index uses the district of the former German capital Bonn as baseline (100 points). The cheapest district is Tirschenreuth in the federal state of Bavaria with 83.37 points, while Munich with 114.40 points (also in Bavaria) is the most expensive district. Hence, the most expensive district is $37 \%$ more expensive than the cheapest, revealing a substantial price difference within Germany. Figure A.1 in the Appendix shows a map of Germany indicating the price level of each district. Three observations are worth mentioning: price levels are generally lower in East than in West Germany and lower in Northern than in Southern Germany. Moreover, urban areas are more expensive than rural ones. 
To ease interpretation of the estimates of our model (for details see section 3) we rescale the price index. The cheapest district is defined as base of 1 , the other price levels are rescaled accordingly. We match the rescaled price index data and data from the SOEP using district identifiers. ${ }^{6}$ The SOEP is a representative panel study of German households that started in 1984 . For this study we use the five waves 2004 to 2008. In each wave, about 22,000 individuals in 12,000 households are interviewed. Data cover a wide range of topics such as individual attitudes, job characteristics, employment status and income, family characteristics, health status and living conditions. Wagner et al. (1993) and Schupp and Wagner (2002) provide an in-depth description of the SOEP.

Since the first wave in 1984 participants are asked about their life satisfaction on an eleven point Likert scale, which constitutes our dependent variable. The life satisfaction question reads: "How satisfied are you with your life, all things considered?". Life satisfaction is often used as a measure for individual welfare or utility. ${ }^{7}$ It is also gaining importance as an evaluation tool for economic policy. For example, in 2008, French President Nicholas Sarkozy asked a commission of economists to develop better measures for economic performance and social progress than, for example, GDP. In their report, the so called 'Sarkozy commission' notes that “... the time is ripe for our measurement system to shift emphasis from measuring economic production to measuring people's well-being." (p.12, Stiglitz et al. (2009)). Similarly, instead of the GDP, the government in Bhutan has decided to use the life-satisfaction of its population as main policy goal.

Since we are interested in the effect of purchasing power on life satisfaction, our explanatory variable of interest is real income. The goal of our real income measure is to capture purchasing power of a given nominal income as precisely as possible. We start with household disposable nominal income, i.e., after tax household income including all kinds of government transfer income. ${ }^{8}$ We then form the corresponding per person equivalence income as suggested by the OECD (see Grabka (2008) for an application to SOEP data). The idea of the equivalence income is to assign each household member the income that corresponds to the disposable income the household member would have if he were single. The equivalence income corrects household income

\footnotetext{
${ }^{6}$ Due to data privacy protection rules, working with the SOEP data at district level is only possible via a special mode of online access to the SOEP data, SOEP remote.

${ }^{7}$ For a detailed discussion on the relationship between satisfaction with life and utility see, for example, Clark et al. (2008) and Oswald (2008).

${ }^{8}$ We adjust all income measures for inflation using 2004 as the baseline year. We use the national inflation rate since there are no comprehensive data on inflation rates at lower levels, not even for all 16 federal states.
} 
for the number of household members by dividing through a factor. The factor takes a value of 1 for the first household member, 0.7 is added for each additional adult and 0.5 for each child. To obtain our measure of real income, we divide the nominal equivalence income by the district specific price level.

In our regressions of life satisfaction on income we use a well-established set of control variables. These control variables are dummies for marital status (Married, Separated, Divorced, Widowed; Single as omitted category), dummies for employment status (Employed full time, Employed part time, Maternity leave, Non-participant; Unemployed as omitted category), the level of disability (Level of disability), the number of children in the household (Number of children), a dummy for whether a disabled person is living in the household (Invalid in household), and district dummies. Summary statistics of all variables can be found in Table 2. Moreover, we include year dummies. We use all subsamples of the SOEP data and use cross-sectional weights provided in the SOEP data.

Table 2: Summary Statistics of Dependent and Explanatory Variables

\begin{tabular}{lccc}
\hline \hline Variable & Observations & Mean & Std. Dev. \\
\hline Life satisfaction & 104,192 & 6.92 & 1.80 \\
Price index & 104,192 & 1.11 & 0.07 \\
Nominal equivalence income (adjusted for inflation) & 104,192 & 18,520 & 28,691 \\
Real equivalence income (adjusted for inflation) & 104,192 & 16,641 & 27,459 \\
Number of children & 104,192 & 0.55 & 0.92 \\
Single & 104,192 & 0.24 & 0.43 \\
Married & 104,192 & 0.60 & 0.49 \\
Separated & 104,192 & 0.02 & 0.13 \\
Divorced & 104,192 & 0.08 & 0.27 \\
Widowed & 104,192 & 0.07 & 0.25 \\
Level of disability & 104,192 & 7.12 & 20.97 \\
Invalid in household & 104,192 & 0.04 & 0.20 \\
Unemployed & 104,192 & 0.06 & 0.24 \\
Employed full time & 104,192 & 0.39 & 0.49 \\
Employed part time & 104,192 & 0.15 & 0.36 \\
Maternity leave & 104,192 & 0.02 & 0.12 \\
Non-participant & 104,192 & 0.39 & 0.49 \\
\hline
\end{tabular}

Data source: SOEP and price index data. 


\section{Empirical Strategy}

Our research question is whether, for a given nominal income, differences in purchasing power affect individual satisfaction with life. Using the price index data discussed above allows to determine purchasing power of a given nominal income for each of the 393 German districts. To ensure that the price index captures only the purchasing power effect on satisfaction with life and not the effect of other unobserved district characteristics, such as differences in infrastructure, our specification includes a dummy variable for each district. ${ }^{9}$

We choose a specification that is easy to compare to existing studies. The difference to standard life satisfaction regressions is that, additional to nominal income, we include an additional regressor: the difference between real and nominal income, $(R-N) \cdot{ }^{10}$ Real income is nominal income $N$ divided by the price index $P$. A coefficient of $(R-N)$ that is significantly different from zero implies that, controlling for nominal income, the local price level affects satisfaction with life. $(R-N)$ is always smaller than or equal to zero and is decreasing in $P$ since $R-N=\left(\frac{1}{P}-1\right) \times N$ and $P$ is rescaled to be larger than or equal to 1 . Thus, a positive coefficient of $(R-N)$ indicates that there is a purchasing power effect: for a given nominal income, a higher price level reduces satisfaction with life.

More precisely, we estimate the following linear individual fixed effects specification for individual $i$ 's life satisfaction in district $j$ in year $t, H_{i j t}$ :

$$
H_{i j t}=\alpha_{0}+\alpha N_{i j t}+\gamma N_{i j t}^{2}+\delta\left(R_{i j t}-N_{i j t}\right)+\mathbf{x}_{i j t} \boldsymbol{\beta}+c_{i}+d_{j}+h_{t}+\epsilon_{i j t} .
$$

$N$ is nominal equivalence income adjusted for inflation, which we simply call nominal income throughout the paper. $R$ is real income, $\mathrm{x}$ is a vector including all further control variables as described in section 2 (see also Table 2), $c$ is an individual fixed effect, $d$ is a district dummy, $h$ is a year dummy, $\alpha_{0}$ a constant term, and $\epsilon$ the error term. To avoid having inconsistent estimates because of unobserved time-invariant individual characteristics that are correlated with the explanatory variables and satisfaction with life we use a fixed effects estimator. ${ }^{11}$ Doing so,

\footnotetext{
${ }^{9}$ To identify the effect of the price index one district dummy is dropped.

${ }^{10}$ Using a typical life satisfaction regression in which nominal income is simply substituted by real income does not deliver any insights on the influence of the price level on life satisfaction. The reason is that real and nominal income are highly correlated and the coefficient of real income would be largely driven by differences in nominal income (that ranges from close to zero to more than a million Euros, while the regional price level 'only' ranges from 1 to 1.37 using our rescaled price index).

${ }^{11}$ Ferrer-i-Carbonell and Frijters (2004) show that using a fixed-effects estimator is of great importance when estimating life satisfaction regressions. In the same paper, they show that estimating an ordinal instead of a linear
} 
any time-invariant regressor is dropped. The rescaled price index, $P$, is time-invariant. With $P$ as a separate regressor, we would identify the potential purchasing power effect on individual life satisfaction only via the relatively small number of movers in our sample, about $1.4 \%$ of all individuals. In our specification, identification of the effect of time-invariant $P$ through the $(R-N)$ term is additionally achieved using variation in individual nominal income over time.

Usually, regressions with life satisfaction as dependent variable use the logarithm of income because a concave relationship between satisfaction with life and income is a robust finding of the previous empirical literature and typically assumed in utility theory. However, applying the logarithm to real income $R$ would drop out the time-invariant price index in our fixed effects specification. ${ }^{12}$ To directly compare the size of coefficients of nominal income $N$ and the $(R-N)$ term, we do not use the logarithm of nominal income either. Instead we add the square of nominal income as regressor to allow for concavity.

A further important implication of the concave relationship between life satisfaction and income is that we only expect the price level to have a sizable effect on life satisfaction for people in the lower income quantiles. To illustrate concavity for our data set we estimate the following life satisfaction specification, which is typically used in the literature.

$$
H_{i j t}=\alpha_{0}+\alpha \ln \left(N_{i j t}\right)+\mathbf{x}_{i j t} \boldsymbol{\beta}+c_{i}+d_{j}+h_{t}+\epsilon_{i j t} .
$$

All variables are defined as in equation (1). Since we do not account for different regional price levels we are able to use a logarithmic functional form.

Figure 1 shows the relation between life satisfaction and income. In particular, it displays the estimated level of life satisfaction depending on the level of nominal income (setting all other control variables equal to zero), i.e., $\hat{\alpha} \ln (N)$ from specification (2) in points of life satisfaction that ranges from 0 to 10 . The sensitivity of life satisfaction with respect to nominal income decreases strongly as income rises. Hence, for higher incomes we do not expect that the different price levels, which result in different levels of real income, have a sizable effect. We therefore first investigate the results for the entire sample to document the direction of the effect and to check whether all control variables show effects in the expected directions. Thereafter, we stratify the data by income percentiles with a particular focus on the lower income quantiles. We start at the $10 \%$ quantile and successively add the next decile to the sample.

model only marginally changes results.

${ }^{12} \log (R)=\log \left(\frac{N}{P}\right)=\log (N)-\log (P)$ 
Figure 1: Life Satisfaction and Nominal Income

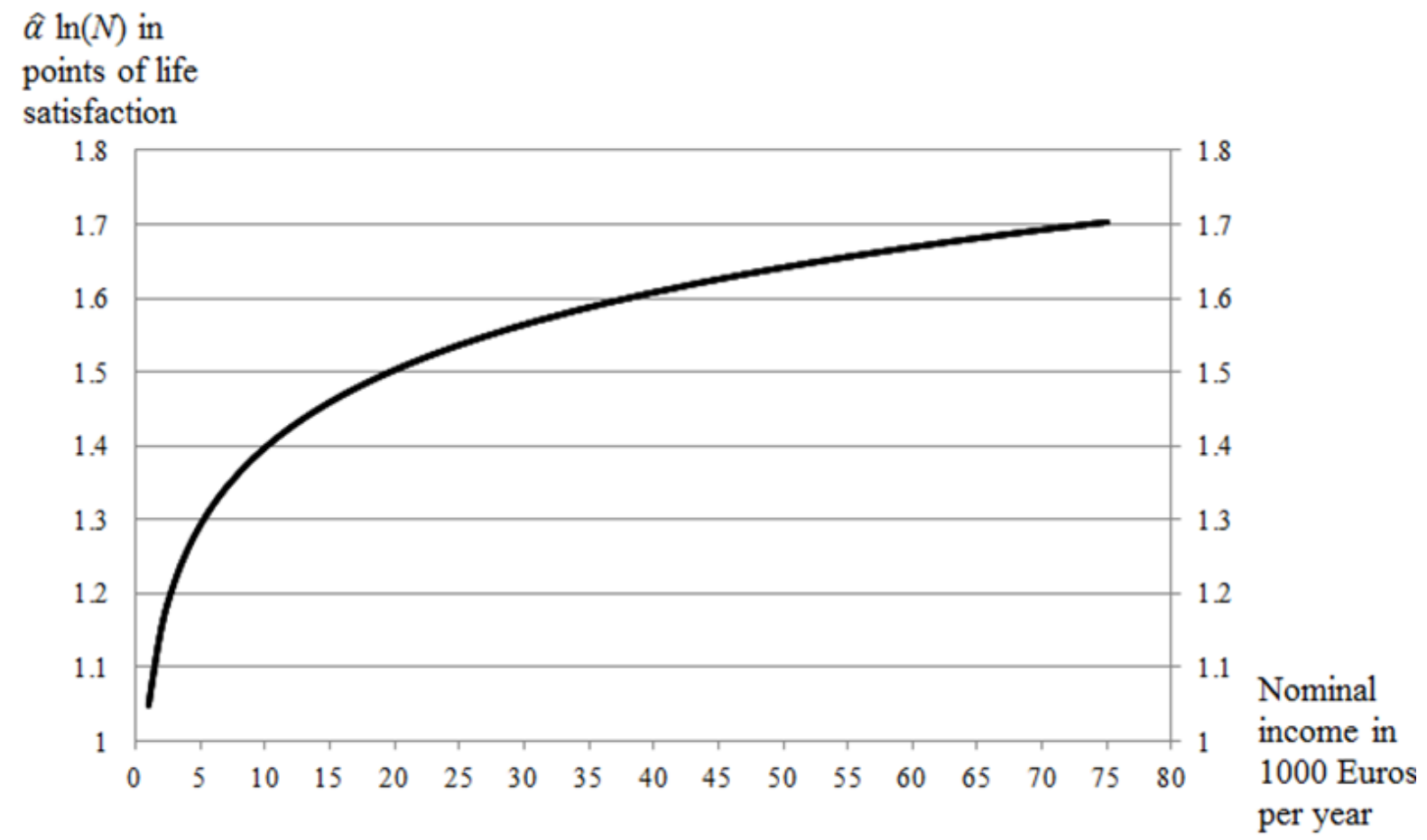

The figure shows $\hat{\alpha} \ln (N)$ from specification (2) in points of life satisfaction that ranges from 0 to 10 , i.e., the estimated level of life satisfaction that is due to a particular level of nominal income (setting all other control variables equal to zero).

\section{Results}

In this section, we start with analyzing whether differences in local price levels affect satisfaction with life (purchasing power effect). In a second step, we discuss potential non-neutrality of money.

\subsection{The purchasing power effect}

Table 3 displays the estimation results of specification (1). Different columns show results for different partitions of the income distribution. The results for the whole sample in the rightmost column are well in line with findings from the previous literature. Compared to being single, people are more satisfied if they are married and tend to be less satisfied if they are separated or widowed. The number of children has only a marginally significant positive influence on life satisfaction. Being disabled oneself and the obligation to take care of an invalid in the household has a strongly significant, negative influence on life satisfaction. Compared to being unemployed, 
we find significant positive effects (all at the 1\% level) of being employed full or part time, of maternity leave, and of being a non-participant in the labor market. Finally, for the sample as a whole, we find a significant positive, but decreasing marginal effect of nominal income on life satisfaction. Moreover, the coefficient of $(R-N)$, our main variable of interest, is positive. The positive sign points in the direction of a purchasing power effect. For the population as a whole, however, this effect is not strong enough to significantly affect individual satisfaction with life (p-value $=0.25)$.

Since the relationship between life satisfaction and nominal income is concave, the sensitivity to the price level is expected to be higher for less affluent people, i.e., in lower quantiles of the sample (cf. Figure 1). We therefore focus on the lower income quantiles of the sample. We start with the $10 \%$ decile and successively add the next deciles to the sample, see columns 1-5 of Table $3 .{ }^{13} \mathrm{~A}$ first observation is that the coefficients of the control variables, display relatively stable patterns for all subsamples. As expected, this is not the case for the coefficients of the income variables. The coefficient of $(R-N)$, our main variable of interest, is decreasing as the income quantile increases. In other words, the lower the income of a person, the stronger is the reaction to price levels, i.e., the larger is the coefficient of $(R-N)$. The coefficient of $(R-N)$ is significant for the $30 \%$ and $40 \%$ quantile, respectively (p-value $<0.05$ ). Although the coefficient is equally large at the $10 \%$ and $20 \%$ quantile, respectively, it is not significant. This is due to the lower number of observations and less within-subject variation of income over time. Finally, for the $50 \%$ quantile the purchasing power effect drops sharply and becomes statistically insignificant.

Figure 2 displays our main finding on a finer grid. In particular, it shows the coefficient of $(R-N)$ for different partitions of the income distribution in steps of 5 percentage points cutting it from above. For the $40 \%$ poorest, the coefficient of $(R-N)$ starts getting significant at the $5 \%$ level. ${ }^{14}$ Moreover, no matter how the income distribution is partitioned, the coefficient of $(R-N)$ is positive, indicating a purchasing power effect. Figure 2 also shows that the coefficient of $(R-N)$ has an upward trend from richer to poorer partitions of the income distribution. This corroborates our observation that the effect of purchasing power on life satisfaction is much stronger for poorer than for richer people. Finally, standard errors of $(R-N)$ increase substantially in poorer subsamples of the income distribution. This is due to a lower number of observations and

\footnotetext{
${ }^{13}$ An alternative would be to construct standard income quantiles that are not overlapping. However, the identification of the purchasing power effect rests on sufficient within-subject variation of income, which is, by construction, lower in non-overlapping quantiles and does not suffice to identify the effect of the price index.

${ }^{14}$ The coefficient of $(R-N)$ is significant at the $10 \%$ level for the poorest $45 \%$.
} 
Table 3: Fixed Effects Regression

\begin{tabular}{|c|c|c|c|c|c|c|}
\hline & \multicolumn{6}{|c|}{ Bottom Quantiles } \\
\hline & $10 \%$ & $20 \%$ & $30 \%$ & $40 \%$ & $50 \%$ & $100 \%$ \\
\hline & $(7,693 €)$ & $(9,667 €)$ & $(11,195 €)$ & $(12,699 €)$ & $(14,247 €)$ & $(-)$ \\
\hline \multirow[t]{2}{*}{$N / 1000$} & 0.091 & 0.097 & 0.098 & $0.110^{* *}$ & $0.062^{*}$ & $0.004^{* *}$ \\
\hline & $(0.127)$ & $(0.078)$ & $(0.055)$ & $(0.045)$ & $(0.035)$ & $(0.002)$ \\
\hline \multirow[t]{2}{*}{$(N / 1000)^{2}$} & 0.002506 & -0.0004259 & -0.0007952 & -0.003371 & -0.00141 & $-0.0000009^{*}$ \\
\hline & $(0.011040)$ & $(0.005145)$ & $(0.003293)$ & $(0.002428)$ & $(0.001641)$ & $(0.000001)$ \\
\hline \multirow[t]{2}{*}{$(R-N) / 1000$} & 0.547 & 0.358 & $0.482^{* *}$ & $0.367^{* *}$ & 0.155 & 0.015 \\
\hline & $(0.541)$ & $(0.341)$ & $(0.238)$ & $(0.168)$ & $(0.137)$ & $(0.012)$ \\
\hline \multirow[t]{2}{*}{ Number of children } & -0.071 & -0.041 & -0.002 & 0.009 & 0.017 & $0.050^{*}$ \\
\hline & $(0.078)$ & $(0.062)$ & $(0.055)$ & $(0.044)$ & $(0.037)$ & $(0.026)$ \\
\hline \multirow[t]{2}{*}{ Married } & -0.045 & 0.093 & 0.105 & 0.253 & $0.274^{* *}$ & $0.212^{* * *}$ \\
\hline & $(0.444)$ & $(0.206)$ & $(0.168)$ & $(0.156)$ & $(0.138)$ & $(0.068)$ \\
\hline \multirow[t]{2}{*}{ Separated } & -0.18 & -0.227 & -0.139 & -0.105 & -0.055 & $-0.267^{* *}$ \\
\hline & $(0.542)$ & $(0.312)$ & $(0.254)$ & $(0.229)$ & $(0.197)$ & $(0.120)$ \\
\hline \multirow[t]{2}{*}{ Divorced } & 0.382 & 0.099 & -0.013 & 0.137 & 0.171 & 0.18 \\
\hline & $(0.562)$ & $(0.304)$ & $(0.246)$ & $(0.221)$ & $(0.192)$ & $(0.118)$ \\
\hline \multirow[t]{2}{*}{ Widowed } & -0.195 & -0.094 & -0.167 & -0.034 & -0.001 & -0.174 \\
\hline & $(0.688)$ & $(0.356)$ & $(0.263)$ & $(0.237)$ & $(0.212)$ & $(0.134)$ \\
\hline \multirow[t]{2}{*}{ Level of disability } & $-0.006^{*}$ & $-0.005^{* *}$ & $-0.008^{* * *}$ & $-0.007^{* * *}$ & $-0.006^{* * *}$ & $-0.005^{* * *}$ \\
\hline & $(0.004)$ & $(0.002)$ & $(0.003)$ & $(0.002)$ & $(0.002)$ & $(0.001)$ \\
\hline \multirow[t]{2}{*}{ Invalid in household } & $-0.895^{* * *}$ & $-0.706^{* * *}$ & $-0.708^{* * *}$ & $-0.603^{* * *}$ & $-0.600^{* * *}$ & $-0.569^{* * *}$ \\
\hline & $(0.318)$ & $(0.209)$ & $(0.162)$ & $(0.134)$ & $(0.114)$ & $(0.079)$ \\
\hline \multirow[t]{2}{*}{ Employed full time } & $0.311^{*}$ & $0.387^{* * *}$ & $0.557^{* * *}$ & $0.660^{* * *}$ & $0.648^{* * *}$ & $0.655^{* * *}$ \\
\hline & $(0.169)$ & $(0.100)$ & $(0.097)$ & $(0.081)$ & $(0.073)$ & $(0.055)$ \\
\hline \multirow[t]{2}{*}{ Employed part time } & 0.179 & $0.272^{* * *}$ & $0.408^{* * *}$ & $0.419^{* * *}$ & $0.425^{* * *}$ & $0.464^{* * *}$ \\
\hline & $(0.149)$ & $(0.098)$ & $(0.090)$ & $(0.077)$ & $(0.070)$ & $(0.055)$ \\
\hline \multirow[t]{2}{*}{ Maternity leave } & 0.228 & $0.419^{* * *}$ & $0.472^{* * *}$ & $0.514^{* * *}$ & $0.497^{* * *}$ & $0.542^{* * *}$ \\
\hline & $(0.271)$ & $(0.147)$ & $(0.116)$ & $(0.104)$ & $(0.094)$ & $(0.073)$ \\
\hline \multirow[t]{2}{*}{ Nonparticipant } & -0.045 & 0.139 & $0.298^{* * *}$ & $0.322^{* * *}$ & $0.335^{* * *}$ & $0.392^{* * *}$ \\
\hline & $(0.126)$ & $(0.094)$ & $(0.084)$ & $(0.077)$ & $(0.070)$ & $(0.055)$ \\
\hline Observations & 8,105 & 17,140 & 26,583 & 36,579 & 46,541 & 104,192 \\
\hline
\end{tabular}

Dependent variable is individual life satisfaction. ${ }^{*},{ }^{* *}$, and ${ }^{* * *}$ indicate significance at the $10 \%$, $5 \%$, and $1 \%$ level. Robust standard errors, clustered at district level, are shown in parentheses. For each partition, the highest nominal disposable equivalence income is displayed in parentheses. $\mathrm{N}$ is nominal disposable equivalence income, $\mathrm{R}$ is real disposable equivalence income. Ceteris paribus, a positive coefficient of (R-N) implies lower individual life satisfaction the higher the price level. Omitted category for marital status is being single, and for employment being unemployed. Year and district dummies are included. 
Figure 2: Coefficient of $(R-N)$

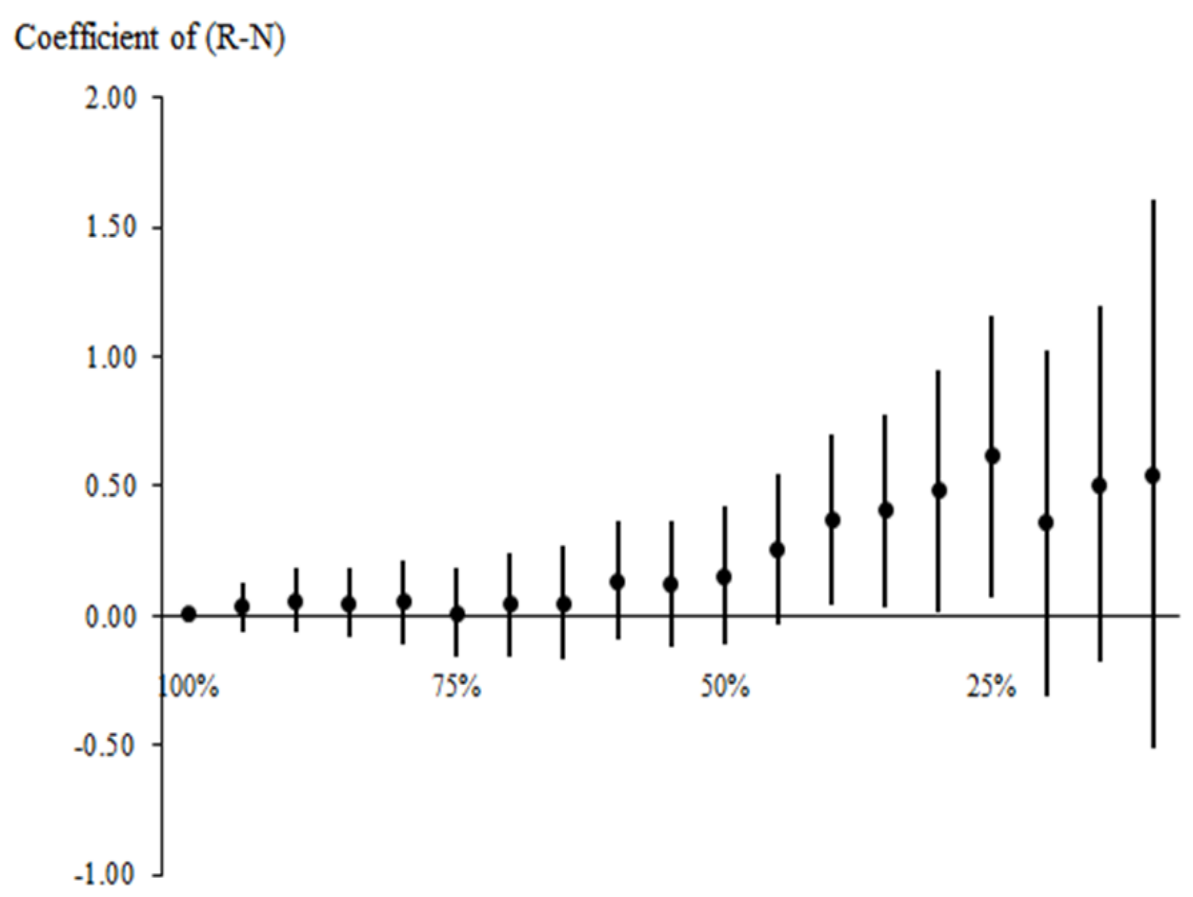

Bottom \% of

the income

distribution

This figure shows the coefficient of $(R-N)$ for different partitions of the income distribution. Estimated coefficients are based on our main specification as defined in equation (1) and correspond to those displayed in Table 3. Black dots denote the point estimates, while the adjoining lines indicate the $95 \%$ confidence intervals. The coefficient is significant (at the $5 \%$ level) from the bottom $40 \%$ to the bottom $25 \%$ quantile. The estimated coefficient increases for lower parts of the income distribution.

a lower within variation in nominal income that is used to identify the coefficient of $(R-N){ }^{15}$ For these reasons, we do not find a significant coefficient of $(R-N)$ from the bottom $20 \%$ quantile onwards. However, the fact that the coefficients of $(R-N)$ are high suggests that the price level also affects life satisfaction in the very lowest part of the income distribution. In sum, we find that people with a low nominal income (up to the $40 \%$ quantile) fare significantly better when living in districts with lower price levels.

As a robustness check, we estimate our baseline specification as presented in Table 3, but exclude the $N^{2}$ term. The rationale is to ensure that our results are not affected by a multicollinearity due to a high correlation of $N$ and $N^{2}$. While using a variable and its square as

\footnotetext{
${ }^{15}$ For example, the within-subject standard deviation of nominal income drops by $25 \%$ from 1352 to 1015 when going from the bottom $50 \%$ quantile to the bottom $20 \%$ quantile.
} 
separate regressors is a very common approach, the two are usually highly correlated. In our data, the correlation coefficient of $N$ and $N^{2}$ ranges between 0.84 and 0.98 . In contrast, the correlation coefficients of $(R-N)$ and $N$ or $(R-N)$ and $N^{2}$ are much lower, ranging between -0.36 and -0.73 and -0.08 and -0.72 , respectively, depending on the quantile we consider. The estimated coefficients of the income variables are displayed in Table 4. As one would expect, without a negative $N^{2}$ term, the coefficients of nominal income are smaller. Reassuringly, the coefficients of $(R-N)$ are very similar to our baseline estimates - especially in the bottom half of our sample in which the coefficient becomes significantly different from zero. Again, positive coefficients of $(R-N)$ indicate the purchasing power effect. As in our baseline specification, the purchasing power effect is present for all income quantiles in the bottom half of the income distribution and becomes significant from the $40 \%$ quantile $(\mathrm{p}=0.03)$ onwards. Thus, the estimates of our baseline specification are corroborated by a specification which is robust against multicollinearity. ${ }^{16}$

As a next step, we use our baseline specification (Table 3) to quantify the effect of a change

Table 4: Fixed Effects Regression Excluding $N^{2}$

\begin{tabular}{lcccccc}
\hline \hline & & \multicolumn{2}{c}{ Bottom Quantiles } \\
& $10 \%$ & $20 \%$ & $30 \%$ & $40 \%$ & $50 \%$ & $100 \%$ \\
& $(7,693 €)$ & $(9,667 €)$ & $(11,195 €)$ & $(12,699 €)$ & $(14,247 €)$ & $(-)$ \\
\hline$N / 1000$ & $0.117^{*}$ & $0.092^{* * *}$ & $0.086^{* * *}$ & $0.055^{* * *}$ & $0.036^{* *}$ & 0.0008 \\
& $(0.062)$ & $(0.034)$ & $(0.026)$ & $(0.020)$ & $(0.016)$ & $(0.0006)$ \\
$R / 1000-N / 1000$ & 0.558 & 0.368 & $0.480^{* *}$ & $0.364^{* *}$ & 0.153 & -0.005 \\
& $(0.538)$ & $(0.340)$ & $(0.239)$ & $(0.168)$ & $(0.088)$ & $(0.00682)$ \\
\hline Controls & yes & yes & yes & yes & yes & yes \\
\hline F-Test (p-value) & 0.3615 & 0.3919 & 0.0679 & 0.0412 & 0.3385 & 0.3353 \\
\hline Observations & 8,105 & 17,140 & 26,583 & 36,579 & 46,541 & 104,192 \\
\hline \hline
\end{tabular}

Dependent variable is individual life satisfaction. ${ }^{*},{ }^{* *}$, and ${ }^{* * *}$ indicate significance at the $10 \%, 5 \%$, and $1 \%$ level. Robust standard errors, clustered at district level, are shown in parentheses. For each partition, the highest nominal disposable equivalence income is displayed in parentheses. Explanatory variables are the same as in Table 3. Ceteris paribus, a positive coefficient of (R-N) implies lower individual life satisfaction the higher the price level.

\footnotetext{
${ }^{16} \mathrm{~A}$ second robustness check reveals that the results from the baseline specification are also robust against excluding all individuals who have moved at least once during the period under study from the sample. This is reassuring since movers could be a peculiar subset of the population, experiencing particularly strong shocks to life satisfaction caused by shocks to unobserved heterogeneity.
} 
in the price level on a person's life satisfaction ceteris paribus. In particular, we take the point estimates of $(R-N)$ and, for a given nominal income, let $P$ vary. The results are as follows: given a yearly nominal equivalence income of 10,456 $(12,699)$ Euros (corresponding to the bottom $25 \%$ and $40 \%$ quantile, respectively), moving from a district with the mean price level of 1.11 to a $10 \%$ more expensive district reduces life satisfaction by $0.53(0.38)$ points on an 11 point scale. These effects are economically significant. For example, the effect of having a full-time job compared to being unemployment increases life satisfaction by about 0.6 points. Furthermore, the effect of a $10 \%$ price increase exceeds the effect of a corresponding change in nominal income by a large amount. For example, a person living in a district with the mean price level of 1.11 with an income of 10,456 (12,699) Euros only loses $0.06(0.09)$ points for a $9.1 \%$ decrease in nominal income. ${ }^{17}$ Hence, for people in the lower part of the income distribution, there is substantial divergence between the estimated change in life satisfaction caused by a change in the price level compared to a corresponding change in nominal income.

\subsection{Non-neutrality of money}

To allow for a formal test for neutrality of money (i.e., the absence of any deviation from evaluation in real terms), we also estimate our specification for the lower half of the income distribution including the additional term $\left(R^{2}-N^{2}\right)$. We test the null hypothesis that money is neutral, i.e., that the coefficients of $N$ and $(R-N)$ are not significantly different from each other and at the same time, the ones of $N^{2}$ and $\left(R^{2}-N^{2}\right)$ are not significantly different from each other either. We perform a joint F-test on these two restrictions. Rejecting the null hypothesis implies rejecting neutrality of money. In fact the null hypothesis of neutrality of money is rejected for the $40 \%$ poorest individuals $(\mathrm{p}=0.06)$. Thus, we reject neutrality of money exactly for the less affluent part of the sample that is found to react sensitively to price levels. Table 5 contains the results of the estimations and the corresponding F-tests. As explained in the previous subsection, nonneutrality is driven by a stronger reaction to changes in prices compared to changes in income.

These results are corroborated using a specification that is robust against multicollinearity. In particular, in the regression excluding the $N^{2}$ term (Table 4) we also test for equality of coefficients of the two linear terms $N$ and $(R-N)$ which provides a robustness check for the test

\footnotetext{
${ }^{17}$ Nominal income has to fall by $9.1 \%$ to result in the same real income as induced by a $10 \%$ rise in the price level.
} 
for neutrality of money displayed in Table 5. The tests for neutrality of money are displayed in Table 4. Similar to the results in Table 5, we reject the null hypothesis of neutrality of money for the bottom quantiles $40 \%$ ( $\mathrm{p}=0.04)$ to $25 \%(\mathrm{p}=0.04)$.

Boes et al. (2007) present a related finding. They compare the effect of nominal income and

Table 5: Fixed Effects Regression Including $\left(R^{2}-N^{2}\right)$

\begin{tabular}{lccccc}
\hline \hline & \multicolumn{5}{c}{ Bottom Quantiles } \\
& $10 \%$ & $20 \%$ & $30 \%$ & $40 \%$ & $50 \%$ \\
& $(7,693 €)$ & $(9,667 €)$ & $(11,195 €)$ & $(12,699 €)$ & $(14,247 €)$ \\
\hline$N / 1000$ & 0.008 & 0.146 & 0.158 & $0.161^{*}$ & $0.173^{* *}$ \\
& $(0.245)$ & $(0.137)$ & $(0.121)$ & $(0.097)$ & $(0.067)$ \\
$(N / 1000)^{2}$ & 0.0111200 & -0.0044460 & -0.0051020 & -0.0066440 & $-0.007886^{* *}$ \\
$R / 1000-N / 1000$ & $(0.0250500)$ & $(0.0107600)$ & $(0.0082150)$ & $(0.0059000)$ & $(0.00358)$ \\
& -0.317 & 0.872 & 1.130 & 0.917 & $1.352^{* *}$ \\
$(R / 1000)^{2}-(N / 1000)^{2}$ & $(2.167)$ & $(1.272)$ & $(1.156)$ & $(0.962)$ & $(0.662)$ \\
& 0.0479800 & -0.0227000 & -0.0248600 & -0.0188000 & $-0.03722^{*}$ \\
\hline Controls & $(0.1226000)$ & $(0.0559700)$ & $(0.0419400)$ & $(0.0312000)$ & $(0.01932)$ \\
\hline F-Test $(\mathrm{p}$-value $)$ & yes & yes & yes & yes & yes \\
\hline Observations & 0.7118 & 0.6190 & 0.1769 & 0.0617 & 0.1312 \\
\hline \hline
\end{tabular}

Dependent variable is individual life satisfaction. ${ }^{*},{ }^{* *}$, and ${ }^{* * *}$ indicate significance at the $10 \%, 5 \%$, and 1\% level. Robust standard errors, clustered at district level, are shown in parentheses. For each partition, the highest nominal disposable equivalence income is displayed in parentheses. Explanatory variables are the same as in Table 3.

a price index at the level of 13 out of 16 federal states in Germany on income satisfaction. Because of the different data, they use the log of income and the log of the price index as independent variables. Neutrality of money would imply, that the coefficients of the two are equal. However, depending on the specification, the estimated coefficients of log price level are $23 \%$ to $43 \%$ higher than the coefficients of log nominal income. These differences are, however, not statistically significant.

A possible overreaction to price levels can also be inferred from using our data set when splitting our sample at the median of the price level. The resulting mean nominal income in the half of the sample corresponding to the higher price levels is $26.1 \%$ higher than in the other half (20.734 against 16.443 Euros). In contrast, the mean price level is only 8.5\% higher (1.15 against 
1.06). If money would be neutral, one would expect the difference in income and price levels to be roughly equal. However, the results show a pronounced overcompensation in nominal income for higher price levels.

The result that poorer people's life satisfaction is more sensitive to prices than to nominal disposable income is in line with the empirical literature on salience effects (Chetty et al. (2009), Blumkin et al. (2012), Finkelstein (2009)) if prices are more salient than disposable income. While prices are experienced at high frequency, at every instance of buying, for many people income is not experienced explicitly before consumption, and income changes are relatively rare events. Additionally, many components of disposable income might be less salient, e.g., taxes and government transfer payments.

\section{Discussion}

We have used a novel and very comprehensive data set on local price levels in Germany to study whether price levels affect satisfaction with life once nominal income is controlled for. Our results show that information on price levels matters when analyzing satisfaction with life. In Germany, the poorest $40 \%$ of the population exhibit a significantly lower life satisfaction when living in a more expensive region. For them, the effect of a $10 \%$ increase in the price level on life satisfaction is substantial: its size is comparable to the effect of having a full-time job instead of being unemployed or about twice the effect of being married compared to being single. While the purchasing power effect (i.e., higher prices reduce satisfaction with life) is also present for the population as a whole, it is not significant at conventional levels. Both results are compatible with the well-established empirical fact that the relationship between satisfaction with life and nominal income is concave.

Our results are of obvious relevance for advising policy, in particular if policy aims at treating equals equally. In that sense, our findings call for a regional indexation of government transfer payments, in particular of those transfers which target low income groups such as the US Supplemental Security Income (SSI), unemployment benefits, or social welfare benefits. Our results also put country-wide uniform public sector or minimum wages into question. In all examples, not adjusting nationwide payments to regional price differences risks treating equals unequally in 
terms of individual satisfaction with life. ${ }^{18}$

Furthermore, for the $40 \%$ poorest of the income distribution, we reject the hypothesis that money is neutral. More precisely, a change in the price level has a stronger effect on life satisfaction than a corresponding change in nominal income. Kahneman et al. (2006) argue that the salience of (nominal) income is particularly high when being confronted with the task to evaluate one's satisfaction with life. At least for poorer people, we find that the salience of the price level seems to be even higher. A possible explanation is that prices are experienced at a much higher frequency than income payments and many components of disposable income such as taxes, social security contributions, or government transfer payments might be less salient than prices.

We believe that the price index data employed in this paper offer lots of scope for future research. Relevant questions comprise, e.g., the effect of the price level on whether wages are perceived as fair and how job search activity or investments in human capital depend on regional price differences.

\footnotetext{
${ }^{18}$ Of course, the validity of these arguments rests on a ceteris paribus assumption, i.e., groups who get compensated for differences in the price level are assumed to be small enough for a change in their nominal income not to affect the local price level.
} 


\section{References}

Akerlof G, Shiller R. 2009. Animal Spirits: How Human Psychology Drives the Economy, and Why it Matters for Global Capitalism. Princeton: Princeton University Press.

Blumkin T, Ruffle B, Ganun Y. 2012. Are Income and Consumption Taxes Ever Really Equivalent? Evidence from a Real-Effort Experiment with Real Goods. European Economic Review 56: 1200-1219.

Boes S, Lipp M, Winkelmann R. 2007. Money Illusion under Test. Economics Letters 94: 332-337.

Chetty R, Looney A, Kroft K. 2009. Salience and Taxation: Theory and Evidence. American Economic Review 99: $1145-1177$.

Clark AE, Frijters P, Shields MA. 2008. Relative Income, Happiness, and Utility: An Explanation for the Easterlin Paradox and Other Puzzles. Journal of Economic Literature 46: 95-144.

Clark AE, Oswald AJ. 1996. Satisfaction and comparison income. Journal of Public Economics 61: 359-381.

Di Tella R, MacCulloch R. 2006. Some uses of happiness data in economics. The Journal of Economic Perspectives 20: $25-46$.

Dolan P, Peasgood T, White M. 2008. Do We Really know What Makes Us Happy? A Review of the Economic Literature on the Factors Associated with Subjective Well-Being. Journal of Economic Psychology 29: 94-122. Fehr E, Tyran JR. 2001. Does money illusion matter? The American Economic Review 91: 1239-1262.

Ferrer-i Carbonell A. 2005. Income and Well-Being: An Empirical Analysis of the Comparison Income Effect. Journal of Public Economics 89: 997-1019.

Ferrer-i-Carbonell A, Frijters P. 2004. How important is methodology for the estimates of the determinants of happiness? The Economic Journal 114: 641-659.

Finkelstein A. 2009. E-ZTax: Tax Salience and Tax Rates. The Quarterly Journal of Economics 124: 969-1010. Fisher I. 1928. The Money Illusion. New York: Adelphi.

Fliessbach K, Weber B, Trautner P, Dohmen T, Sunde U, Elger CE, Falk A. 2007. Social Comparison Affects Reward-Related Brain Activity in the Human Ventral Striatum. Science 318: 1305-1308.

Frey BS, Stutzer A. 2002. What Can Economists Learn from Happiness Research? Journal of Economic Literature 40: $402-435$.

Grabka MM. 2008. Data Documentation 34. DIW, Berlin.

Kahneman D, Krueger AB, Schkade D, Schwarz N, Stone AA. 2006. Would you be happier if you were richer?A focusing illusion. Science 312: 1908-1910.

Kawka R, Beisswenger S, Costa G, Kemmerling H, Müller S, Pütz T, Schmidt H, Schmidt S, Trimborn M. 2009. Regionaler Preisindex, Berichte Band 30. Bundesinstitut für Bau-, Stadt- und Raumforschung, Bonn.

Layard R, Mayraz G, Nickell S. 2008. The Marginal Utility of Income. Journal of Public Economics, Special Issue: Happiness and Public Economics 92.

Luttmer EFP. 2005. Neighbors as negatives: Relative earnings and well-being. The Quarterly Journal of Economics 120: $963-1002$.

Oswald A. 1997. Happiness and economic performance. The Economic Journal 107: 1815-1831.

Oswald A. 2008. On the curvature of the reporting function from objective reality to subjective feelings. Economic Letters 100: 369-372.

Schupp J, Wagner GG. 2002. Maintenance of and Innovation in Long-Term Panel Studies The Case of the German 
Socio-economic panel (GSOEP). Allgemeines Statistisches Archiv 86: 163-175.

Senik C. 2004. When Information Dominates Comparison, Learning from Russian Subjective Panel Data. Journal of Public Economics 88: 2099-2123.

Shafir E, Diamond P, Tversky A. 1997. Money illsuion. The Quarterly Journal Of Economics 112: 341-374.

Stiglitz J, Sen A, Fitoussi JP, Agarwal B, Arrow KJ, Atkinson AB, Bourguignon F, Cotis JP, Deaton AS, Dervis K, Fleurbaey M, Folbre N, Gadrey J, Giovannini E, Guesnerie R, Heckman JJ, Heal G, Henry C, Kahneman D, Krueger AB, Oswald AJ, Putnam RD, Stern N, Sunstein C, Weil P. 2009. Report by the Comission on the Measurement of Economic Performance and Social Progress. www.stiglitz-sen-fitoussi.fr.

Stutzer A. 2004. The role of income aspirations in individual happiness. Journal of Economic Behavior and Organization 54: 89-109.

Stutzer A, Frey BS. 2010. Recent Advances in the Economics of Individual Subjective Well-Being. Social research: An International Quarterly 77: 679-714.

Wagner GG, Burkhauser RV, Behringer F. 1993. The English Language Public Use File of the German SocioEconomic Panel. The Journal of Human Resources 28: 429-433.

Weber B, Rangel A, Wibral M, Falk A. 2009. The medial prefrontal cortex exhibits money illusion. PNAS 106: 5025-5028. 


\section{Appendix}

Figure A.1: Regional Price Index

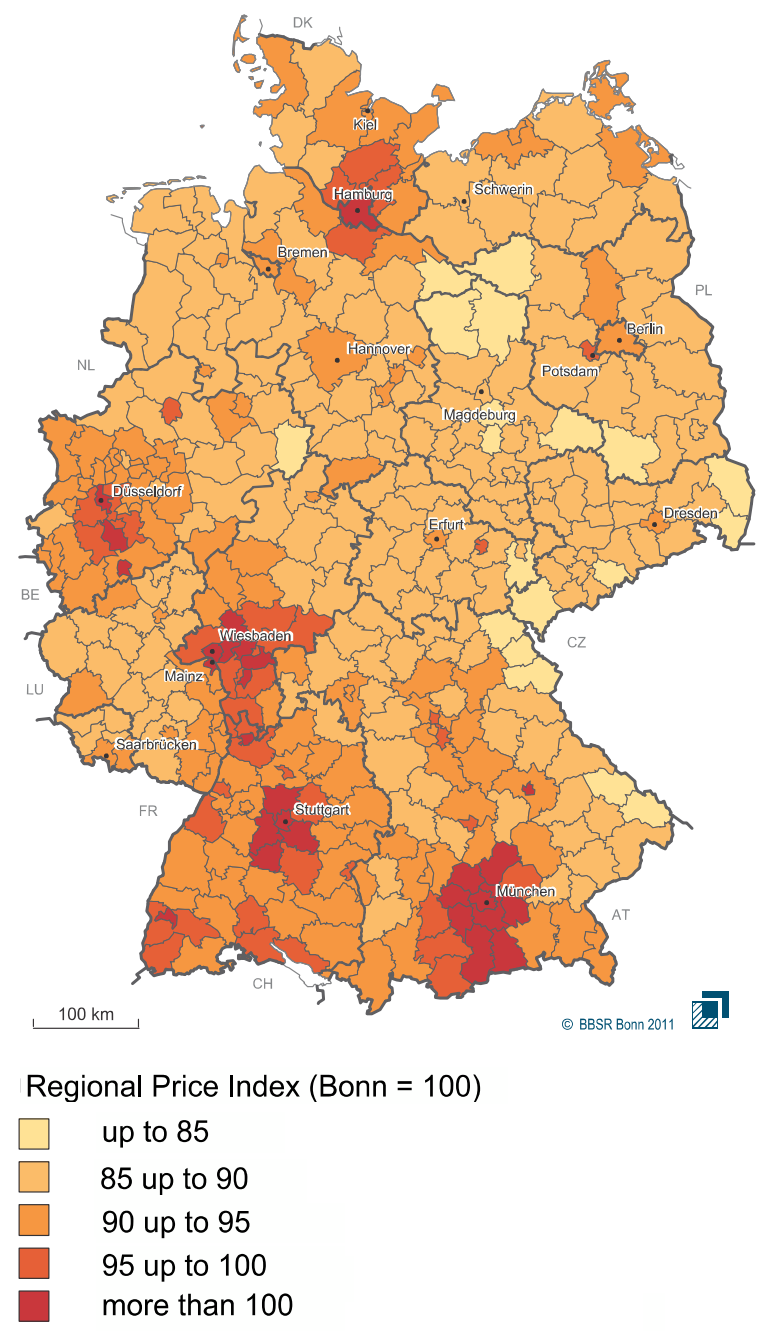

Figure from Bundesinstitut für Bau-, Stadt- und Raumforschung (BBSR), Raumordnungsbericht 2011, Bonn 2012. The colors display ranges of the originally scaled price index. Borders of the districts are marked by grey lines while borders of federal states are marked by dark grey lines. 